\title{
A PROSPECTIVE STUDY OF METHICILLIN-SENSITIVE STAPHYLOCOCCUS AUREUS INFECTIONS ASSOCIATED WITH PATIENT'S BEHAVIOURAL AND SOCIOECONOMIC FACTORS IN RURAL AND URBAN TERTIARY CARE SETUPS
}

\author{
Anil Kumar Hanumanthuำ B. Srinivas ${ }^{2}$ \\ ${ }_{1}^{1}$ Assistant Professor, Department of General Medicine, Rajiv Gandhi Institute of Medical Sciences, Srikakulam, Andhra Pradesh. \\ 2Tutor, Department of Microbiology, Rajiv Gandhi Institute of Medical Sciences, Srikakulam, Andhra Pradesh.
}

\section{ABSTRACT}

\section{BACKGROUND}

Staphylococcus aureus (S. aureus) is responsible for a sizable number of infections globally. In developing countries, multiresistant organisms which can often be traced to complex socioeconomic and behavioural factors, contribute to the escalating problem of antibiotic resistance worldwide.

\section{MATERIALS AND METHODS}

A total of 16665 pus samples were analysed, 6538 pus samples were from rural setup and 10127 from urban setups, all age groups included. Ethical clearance given by the Institutional Ethical Committee (IEC) at Saveetha University, Chennai. An open-ended questionnaire was prepared which collected information on education, occupation, income, history of alcohol intake, smoking habits and history of diseases (i.e. score of Kuppuswamy's scale of 2014-15). Staphylococcus aureus was confirmed by Gram staining, biochemical tests; all the samples were aseptically handled and processed.

\section{RESULTS}

In this study, 16665 samples were analysed out of which 6538 were from rural and 10127 were from urban regions. In rural setup, MSSA constituted 401 (6.1\%) and MRSA 531 (8.1\%). Whereas in urban setup, MSSA constituted 524 (5.2\%) and MRSA 771 (7.6\%). Demographic and Socioeconomic parameters like occupation, income, history of alcohol intake, any diseases and antibiotic usage were collected. $S$. aureus infections were found to be highly significant $(\mathrm{P}<0.001)$, smoking habits were not significant $(\mathrm{P}>0.05)$ in rural and urban tertiary care centres respectively.

\section{CONCLUSION}

We need to slow down the spread and amplification of these strains as much as possible in rural areas by good infection control, conservative measures, prudent use of antibiotics and good hygiene.

\section{KEYWORDS}

MSSA, Infections, Behavioural, Socio-economic Factors.

HOW TO CITE THIS ARTICLE: Hanumanthu AK, Srinivas B. A prospective study of Methicillin-sensitive Staphylococcus aureus infections associated with patient's behavioural and socioeconomic factors in rural and urban tertiary care setups. J. Evolution Med. Dent. Sci. 2017;6(95):6943-6947, DOI: 10.14260/jemds/2017/1507

\section{BACKGROUND}

Bacterial infection is common in isolates from healthy persons and from patients with community-acquired or hospitalacquired infections in developing countries like India, where the need for antibiotics is driven by the high incidence of infectious disease.[1] The selection and spread of Multiresistant organisms in developing countries, which can often be traced to complex socioeconomic and behavioural factors, contribute to the escalating problem of antibiotic resistance worldwide.[2] In developing countries, the irrational use of antibiotics by health professionals, unskilled practitioners, laypersons, poor drug quality, unhygienic conditions and inadequate surveillance account for the spread of resistant bacteria. Nevertheless, misuse of antibiotics is one of the

'Financial or Other Competing Interest': None.

Submission 06-11-2017, Peer Review 05-12-2017,

Acceptance 11-12-2017, Published 23-12-2017.

Corresponding Author:

Dr. Anil kumar Hanumanthu,

Assistant Professor,

Department of General Medicine

Rajiv Gandhi Institute of Medical Sciences (RIMS),

Srikakulam, Andhra Pradesh-532001, India.

E-mail: vasmedmicro@yahoo.com

DOI: $10.14260 /$ jemds $/ 2017 / 1507$ reasons for the increasing rates of resistance, especially in rural areas. ${ }^{2}$ Staphylococcus aureus (S. aureus) is responsible for a sizable number of infections globally.[3] In 1960s, methicillin was the drug of the choice, soon after discover it got resistance in 1961s, then alternative effective antiStaphylococcal antibiotics such as vancomycin were introduced. ${ }^{[4]}$ This is the only drug of choice for the infections caused by methicillin-resistant Staphylococcus aureus (MRSA) and often used empirically for the patients in critical-care settings with infections like severe sepsis, pneumonia and those under umbilical catheterisation, etc in developing countries like India.

However, few studies have systematically studied on cardiovascular health status and other deadly diseases related to behavioural factor and SEC. We, therefore, aimed to determine the prevalence of $\mathrm{S}$. aureus infections correlating with behavioural and socioeconomic class in rural and urban tertiary care centres.

\section{MATERIALS AND METHODS Study Settings}

The prospective study was carried out during August 2013 to November 2015 for a period of 2 years 4 months and the approval given by the Institutional ethical committee (IEC) at Saveetha University, Chennai, Tamilnadu. The experiment was 
conducted in two centres. 1) Rural setup or rural tertiary care centre, Rajiv Gandhi Institute of Medical Sciences (RIMS), Srikakulam, Andhra Pradesh. 2) Urban setup or urban tertiary care centre, Andhra Medical College (AMC), Visakhapatnam, Andhra Pradesh

\section{Sample Selection}

A total of 16665 pus samples were analysed, 6538 pus samples were from rural setup and 10127 were from urban setups; all age groups were included. Ethical clearance was given by the Institutional Ethical Committee (IEC) at Saveetha University, Chennai, Tamilnadu. An open-ended questionnaire was prepared which collected information on education, occupation, income, history of alcohol intake, smoking habits and history of diseases.

Kuppuswamy's scale of 2014-15-

Education levels: Professors or honours (7), Graduate or postgraduate (6), Intermediate or post high school diploma (5), High school certificate (4), Middle school certificate (3), Primary school certificate (2), Illiterate (1).

Occupation levels: Profession (10), Semi-Profession (6), Clerical or Shop-owner (5), Skilled worker (4), Semi-skilled worker (3), Unskilled worker (2), Unemployed (1).

Income range (Rs.): $\leq 1802$ (1), 1803-5386 (2), 5387- 8988 (3), 8989-13494 (4), 13495-17999 (5), 18000-36016 (10), $\geq 36017$ (12).

The sum of total under socioeconomic class: Upper (I), upper middle (II), lower middle (III), lower (V) respectively.[5,6] All the samples were aseptically handled and processed.

\section{Exclusion Criteria}

Duplicate isolates from the same patient, Methicillin-resistant Staphylococcus aureus (MRSA) and other than pus sample.

Confirmation and storage of S. aureus isolates: Gram staining was done for all the samples and the likely organisms were determined. Then, the pus samples were inoculated onto Nutrient agar, Blood agar, MacConkey agar than selective media (Gelatin Mannitol salt agar) (obtained from Hi-Media Laboratories Pvt. Ltd, Mumbai) and incubated at $37^{\circ} \mathrm{C}$ for 24 hours. The suspected colonies of Staphylococci were taken and Gram staining was done, all the Gram-positive cocci in clusters were further confirmed using a battery of standard biochemical reactions including the production of bound and free coagulase enzymes using slide and tube coagulase tests based on standard methods. A known coagulase-positive strain Methicillin-sensitive Staphylococcus aureus ATTC25923 included as the control (obtained from BEI Resource, USA). All the confirmed Staphylococcus aureus strains were subsequently tested for Methicillin resistance based on recommendations of Clinical Laboratory Standard Institute (CLSI). Cefoxitin disc $(30 \mu \mathrm{g})^{[7]}$ obtained from Hi-Media Laboratories Pvt. Ltd Mumbai was used to isolate MRSA and MSSA. The isolates were considered Methicillin-sensitive Staphylococcus aureus (MSSA) if the zone of inhibition was $\geq$ than $22 \mathrm{~mm}$.

\section{Statistical Analysis}

Data were registered in Microsoft excel 2010 and analysed with Statistical Package for Social for the Science (SPSS) version 17.0 software. Chi square $\left(\mathrm{x}^{2}\right)$ test allowed us to compare the prevalence of patient's behavioural and socioeconomic factors among MSSA.

\section{RESULTS}

In this study, 16665 samples were analysed out of which 6538 were from rural and 10127 were from urban regions. In rural setup, MSSA constituted 401 (6.1\%) and MRSA 531 (8.1\%). Whereas in urban setup, MSSA constituted 524 (5.2\%) and MRSA 771 (7.6\%). Percentage of Staphylococcus aureus $(14.3 \%)$ isolated from pus samples was more in rural setup with a predominance of MRSA (8.1\%) when compared to urban setup. Isolation of MSSA were 43\%, 40.5\% and MRSA $57 \%, 59.5 \%$ in rural and urban setups respectively, found to be not significant as shown in Table 1.

Education status of primary school, middle school and high school level patients were more i.e. 95 (23.69), 95 (23.69) and 90 (22.44) in rural areas respectively. In urban areas, high school, and intermediate or post high school level patients were more i.e. 162 (30.92) and 129 (24.90) respectively, Education levels: Professors or honours, Graduate or postgraduate, Intermediate or post high school diploma, High school certificate, Middle school certificate, Primary school certificate, Illiterate in both centres of $\mathrm{S}$. aureus infections were found to be highly significant $(\mathrm{P}<0.001)$ as shown in Table-2.

Occupation status of Unemployed $(137,34.16 \%)$ was more in rural areas. Skilled workers were high $(171,32.63 \%)$ in urban areas.

Occupation i.e. Unemployed, Unskilled worker, Semiskilled worker, Skilled worker, Clerical or Shop-owner, SemiProfession and Profession of $S$. aureus infections in rural and urban tertiary care centres were found to be highly significant $(\mathrm{P}<0.001)$ as shown in Table- 3 .

Income status of $\leq 1802$ and $898-13494$ range (in rupees) was found in 111 (27.68\%) cases, more in rural areas. In urban areas, income range from 8989-13494 and 13495-17999 was found in 96 (18.32\%), 166 (31.68\%) cases respectively. Cases with income Per Month ranging $\leq 1802$, 1803-5386, 53878988, 8989-13494, 13495-17999, 18000-36016 and $\geq 36017$ with S. aureus infections in rural and urban tertiary care centres were found to be highly significant $(\mathrm{P}<0.001)$ as shown in Table-4. Cases of socioeconomic class of Upper lower (IV) were 214 (53.37\%), i.e. more in rural areas. Lower middle (III) were 231 (44.08\%), i.e. more in urban areas. Socioeconomic Class i.e. Upper (I), Upper Middle (II), Lower Middle (III), Upper Lower (IV) and Lower (V) cases of S. aureus infections in rural and urban tertiary care centres were found to be highly significant $(\mathrm{P}<0.001)$ as shown in Table-5.

History of Alcohol intake was more in urban areas (242, $46.18 \%)$ compared to rural areas. History of alcohol intake was found to be highly significant $(\mathrm{P}<0.001)$, in rural and urban tertiary care centres as shown in Table-6. History of usage of any tobacco products was more in urban areas, i.e. $224(42.75 \%)$. History of tobacco products used were found to be not significant $(\mathrm{P}>0.05)$ as shown in Table-6. History of any disease was more in rural areas i.e. 273 (68.08\%). History of any disease was found to be highly significant $(\mathrm{P}<0.001)$ in rural and urban tertiary care centres as shown in Table- 6 . History of any antibiotic usage was more in rural areas, i.e. 333 (83.04\%). History of any Antibiotic usage was found to be highly significant $(\mathrm{P}<0.001)$, in rural and urban tertiary care centres as shown in Table- 6 . 


\begin{tabular}{|c|c|c|c|c|c|c|}
\hline $\begin{array}{c}\text { Name of Tertiary } \\
\text { Care Centre }\end{array}$ & $\begin{array}{c}\text { All Samples } \\
\text { (No. \& \%) }\end{array}$ & $\begin{array}{c}\text { Pus Samples } \\
\text { (No. \& \%) }\end{array}$ & $\begin{array}{c}\text { Staphylococcus } \\
\text { spp. (No. \& \%) }\end{array}$ & $\begin{array}{c}\text { Staphylococcus } \\
\text { aureus (No. \& \%) }\end{array}$ & $\begin{array}{c}\text { MSSA } \\
\text { (No. \& \%) }\end{array}$ & $\begin{array}{c}\text { MRSA } \\
\text { (No. \& \%) }\end{array}$ \\
\hline $\begin{array}{c}\text { Rural - Rajiv Gandhi Institute of Medical } \\
\text { Sciences (RIMS), Srikakulam, AP }\end{array}$ & $6538(100)$ & $3106(47.5)$ & $1920(29.4)$ & $932(14.3)$ & $401(6.13)$ & $531(8.12)$ \\
\hline $\begin{array}{c}\text { Urban - Andhra Medical College (AMC), } \\
\text { Visakhapatnam, AP }\end{array}$ & $10127(100)$ & $4961(49)$ & $2553(25.2)$ & $1295(12.8)$ & $524(5.17)$ & $771(7.61)$ \\
\hline
\end{tabular}

Table 1. Isolation of MSSA from all Samples $(n=401, n=524)$

\begin{tabular}{|c|c|c|c|c|c|}
\hline \multirow{2}{*}{ Sr. No. } & \multirow{2}{*}{ Education } & \multirow{2}{*}{ Score } & Rural Tertiary Care & Urban Tertiary Care & \multirow{2}{*}{ p value } \\
\hline & & & \begin{tabular}{|l|} 
Total (No. \& \%) \\
\end{tabular} & Total (No. \& \%) & \\
\hline 1 & Illiterate & 1 & $22(5.49)$ & $26(4.96)$ & \multirow{8}{*}{$0.000^{*}$} \\
\hline 2 & Primary school & 2 & $95(23.69)$ & $59(11.26)$ & \\
\hline 3 & Middle school & 3 & $95(23.69)$ & $78(14.89)$ & \\
\hline 4 & High school & 4 & $90(22.44)$ & $162(30.92)$ & \\
\hline 5 & Intermediate or post high school & 5 & $48(11.97)$ & $129(24.92)$ & \\
\hline 6 & Graduate or postgraduate & 6 & $36(8.98)$ & $47(8.97)$ & \\
\hline 7 & Professors or honours & 7 & $15(3.74)$ & $23(4.39)$ & \\
\hline \multicolumn{3}{|c|}{ Total } & $401(100)$ & $524(100)$ & \\
\hline
\end{tabular}

\begin{tabular}{|c|c|c|c|c|}
\hline \multirow{2}{*}{ Sr. No. } & Occupation & \multirow{2}{*}{ Score } & Rural Tertiary Care & Urban Tertiary Care \\
\cline { 3 - 5 } & & & Total (No. \& \%) & Total (No. \& \%) \\
\hline 1 & Unemployed & 1 & $137(34.16)$ & $97(18.51)$ \\
\hline 2 & Unskilled worker & 2 & $29(7.73)$ & $39(7.44)$ \\
\hline 3 & Semi-skilled worker & 3 & $78(19.45)$ & $104(19.85)$ \\
\hline 4 & Skilled worker & 4 & $68(16.96)$ & $171(32.63)$ \\
\hline 5 & Clerical or Shop-owner & 5 & $34(8.48)$ & $66(12.60)$ \\
\hline 6 & Semi-Profession & 6 & $31(7.73)$ & $36(6.87)$ \\
\hline 7 & Profession & 10 & $24(5.99)$ & $11(2.10)$ \\
\hline \multicolumn{2}{|c|}{ Total } & $401(100)$ & $524(100)$ \\
\hline
\end{tabular}

\begin{tabular}{|c|c|c|c|c|}
\hline \multirow{2}{*}{ Sr. No. } & $\begin{array}{c}\text { Income Per Month in Rupees (2013- } \\
\text { 2015) }\end{array}$ & \multirow{2}{*}{ Score } & Rural Tertiary Care & Urban Tertiary Care \\
\cline { 3 - 5 } & $\leq 1802$ & 1 & $111(27.68)$ & $85(16.22)$ \\
\hline 1 & $1803-5386$ & 2 & $48(11.97)$ & $38(7.25)$ \\
\hline 2 & $5387-8988$ & 3 & $83(20.70)$ & $62(11.83)$ \\
\hline 3 & $8989-13494$ & 4 & $111(27.68)$ & $96(18.32)$ \\
\hline 4 & $13495-17999$ & 6 & $24(5.99)$ & $166(31.68)$ \\
\hline 5 & $18000-36016$ & 10 & $14(3.49)$ & $55(10.50)$ \\
\hline 6 & $\geq 36017$ & 12 & $10(2.49)$ & $22(4.20)$ \\
\hline 7 & Total & $401(100)$ & $524(100)$ \\
\hline
\end{tabular}

\begin{tabular}{|c|c|c|c|c|}
\hline \multirow{2}{*}{ Score } & \multirow{2}{*}{ Socioeconomic Class } & Rural Tertiary Care & Urban Tertiary Care & \multirow{2}{*}{ p value } \\
\hline & & Total (No. \& \%) & Total (No. \& \%) & \\
\hline $26-29$ & Upper (I) & $16(3.99)$ & $10(1.91)$ & \multirow{6}{*}{$0.000^{*}$} \\
\hline $16-25$ & Upper Middle (II) & $30(7.48)$ & $113(21.56)$ & \\
\hline $11-15$ & Lower Middle (III) & $95(23.69)$ & $231(44.08)$ & \\
\hline $5-10$ & Upper Lower (IV) & $214(53.37)$ & $140(26.72)$ & \\
\hline$<5$ & Lower $(\mathrm{V})$ & $46(11.47)$ & $30(5.73)$ & \\
\hline \multicolumn{2}{|r|}{ Total } & $401(100)$ & $524(100)$ & \\
\hline
\end{tabular}




\begin{tabular}{|c|c|c|c|c|}
\hline \multirow{2}{*}{\multicolumn{2}{|c|}{ Behavioural factors }} & Rural Tertiary Care & Urban Tertiary Care & \multirow{2}{*}{ p value } \\
\hline & & Total (no \& \%) & Total (no \& \%) & \\
\hline \multirow{2}{*}{$\begin{array}{l}\text { History of Alcohol } \\
\text { intake }\end{array}$} & No & $235(58.60)$ & $282(53.82)$ & \multirow{3}{*}{$0.000^{*}$} \\
\hline & Yes & $166(41.40)$ & $242(46.18)$ & \\
\hline \multicolumn{2}{|l|}{$\begin{array}{r}\text { Total } \\
\end{array}$} & $401(100)$ & $524(100)$ & \\
\hline \multirow{2}{*}{ History of Tobacco use } & No & $215(53.62)$ & $300(57.25)$ & \multirow{3}{*}{0.455} \\
\hline & Yes & $186(46.38)$ & $224(42.75)$ & \\
\hline \multicolumn{2}{|c|}{ Total } & $401(100)$ & $524(100)$ & \\
\hline \multirow{2}{*}{ History of any Disease } & No & $128(31.92)$ & $129(24.62)$ & \multirow{3}{*}{$0.000^{*}$} \\
\hline & Yes & $273(68.08)$ & $295(56.30)$ & \\
\hline \multicolumn{2}{|c|}{ Total } & $401(100)$ & $524(100)$ & \\
\hline \multirow{2}{*}{$\begin{array}{l}\text { History of any } \\
\text { Antibiotic usage }\end{array}$} & No & $68(16.96)$ & $177(33.78)$ & \multirow{3}{*}{$0.000^{*}$} \\
\hline & Yes & $333(83.04)$ & $347(66.22)$ & \\
\hline \multicolumn{2}{|l|}{ Total } & $401(100)$ & $524(100)$ & \\
\hline
\end{tabular}

\section{DISCUSSION}

Drug resistance of Staphylococcal species is beginning to emerge as a big clinical issue. Although much work has been and is being done on these organisms, much is also yet to be done, especially with respect to determining the true risk factors for infection and the mechanisms of resistance. A better understanding of these issues will be a key in preventing and treating these infections in the future.

In the present study, contribution of MSSA was 401 (43.03\%) and 524 (56.97\%) and MRSA was 531 (40.46\%) and $771(69.54 \%)$ in rural (of total 932 S. aureus cases) and urban (of total $1295 \mathrm{~S}$. aureus cases) areas respectively.

Studies obtained from other authors in India showed rise in prevalence of MRSA compared to MSSA:

Bandaru N Rao et al[8] - 52\%, Chaudary A et al[9] - 52.8\%, Majumber D et al[10] - 52.9\%, Anupurba S et al[11] - 54.8\%, Dar JA et al[12] - 54.85\%, Singh S et al[13] - 57.14\%, LeBlanc DM et al[14] - 61\%, Yilmaz S et al[15] - 61.1\%, Borg M et al[16] - 65\%, Mistry RD et al[17] - 66\% and Maninder Kaur et al[18] - 34.1\%.

Demographic and Socioeconomic parameters like occupation, income, history of alcohol intake, any diseases and antibiotic usage were collected. $S$. aureus infections were found to be highly significant $(\mathrm{P}<0.001)$, smoking habits were not significant $(\mathrm{P}>0.05)$ in rural and urban tertiary care centres respectively.

In many rural areas, well-trained health workers were scarce. Availability of antibiotic drugs from unofficial sources and financial constraints also affect antibiotic choices. ${ }^{19}$ Education and hygienic habits have not been successfully implemented in many rural areas compared to urban areas. People are encouraged to purchase from unofficial distributors because drugs often are not available in government hospitals. Drug sellers usually have minimal or no knowledge of the required dosage regimen, indications, or contraindications especially in rural areas. In general, these studies have found that educational status is more strongly associated with disease than is income and occupation. Strict regulations on the use of antibiotics in human medicine as well as in various agriculture productions are required to control the emergence of drug-resistant clones. ${ }^{19}$ In urban areas only handful of microbiology laboratories are available. Halfknowledge and overconfidence in self-medication has been responsible for the emergence of drug resistant strains in the urban area.

\section{CONCLUSION}

We need to slow down the spread and amplification of these strains as much as possible in rural areas by good infection control, conservative measures, prudent use of antibiotics and good hygiene. We should not use antibiotics unless really needed, and when using, it is imperative that we employ an agent with the narrowest possible spectrum.

\section{REFERENCES}

[1] Kunin CM. Resistance to antimicrobial drugs--a worldwide calamity. Ann Intern Med 1993;118(7): 557-61.

[2] Okeke IN, Lamikanra A, Edelman R. Socioeconomic and behavioral factors leading to acquired bacterial resistance to antibiotics in developing countries. Emerging Infectious Diseases 1999;5(1)18-27.

[3] Enright MC, Robinson DA, Randle G, et al. The evolutionary history of Methicillin-Resistant Staphylococcus Aureus (MRSA). Proc Natl Acad Sci USA 2002;99(11):7687-92.

[4] Rehm SJ, Tice A. Staphylococcus aureus: methicillinsusceptible $S$. aureus to methicillin-resistant $S$. aureus and vancomycin-resistant S. aureus. Clinical Infectious Diseases 2010;51(2):S176-S82.

[5] Gururaj, Maheshwaran. Kuppuswamy's socioeconomic status scale - a revision of income parameter for 2014 International Journal of Recent Trends in Science And Technology 2014;11(1):01-02.

[6] Kuppuswamy B. Manual of socioeconomic status (urban). 1st edn. Manasayan, Delhi: 1981:66-72.

[7] CLSI. Performance standards for antimicrobial susceptibility testing. CLSI approved standard M100S23. Clinical and Laboratory Standards Institute, Wayne, PA, USA: 2013.

[8] Rao BN, Srinivas B. A prospective study of Methicillin Resistant Staphylococcus Aureus (MRSA) in a teaching hospital of rural setup. JPSI 2012;1(2):37-40.

[9] Chaudhury A, Kumar AG. In vitro activity of antimicrobial agents against oxacillin resistant staphylococci with special reference to Staphylococcus haemolyticus. Indian J Med Microbiol 2007;25(1):50-2.

[10] Majumber D, Bardoloi JS, Phukan AC. Antimicrobial susceptibility pattern among Methicillin Resistant Staphylococcus isolates in Assam. Ind J Med Microbial 2001;19(3):138-40. 
[11] Anupurba S, Sen MR, Nath G, et al. Prevalence of Methicillin Resistant Staphylococcus Aureus in a tertiary care referral hospital in eastern Uttar Pradesh. Ind J Med Microbiol 2003;21(1):49-51.

[12] Dar JA, Thoker MA, Khan JA, et al. Molecular epidemiology of clinical and carrier strains of Methicillin Resistant Staphylococcus Aureus (MRSA) in the hospital settings of North India. Annual Clinical Microbiology Antimicrobials 2006;5:22.

[13] Singh S, Katiyar R, Kaistha SD. High oxacillin, vancomycin and fluoroquinolone resistance amongst biofilm forming Staphylococcus aureus isolates from ulcerative keratitis infections. Indian J Med Microbiol 2011;29(3):312-3.

[14] LeBlanc DM, Reece EM, Horton JB, et al. Increasing incidence of Methicillin Resistant Staphylococcus Aureus in hand infections: a 3-year county hospital experience. Plast Reconstr Surg 2007;119(3):935-40.

[15] Yilmaz S, Kiliç A, Karagöz A, et al. Investigation of various virulence factors among the hospital and community-acquired Staphylococcus aureus isolates by real-time PCR method. Mikrobiyol Bul 2012;46(4):532-45.
[16] Borg M, Scicluna E, De Kraker M, et al. Antibiotic resistance in the south eastern Mediterranean preliminary results from the ARMed project. European Surveillance 2006;11(7):164-7.

[17] Mistry RD, Scott HF, Zaoutis TE, et al. Emergency department treatment failures for skin infections in the era of community-acquired Methicillin-Resistant Staphylococcus Aureus. Pediatr Emerg Care 2011;27(1):21-6.

[18] Maninder K, Satish G, Prerna A, et al. Prevalence and antimicrobial susceptibility pattern of Methicillin Resistant Staphylococcus Aureus (MRSA) isolates in a tertiary care hospital in Punjab. JEMDS 2013;2(41):78 41-6.

[19] Srinivas B, Murty SN, Prasad U, et al. Demographic profile and drug resistance pattern in Methicillinsensitive Staphylococcus aureus in rural and urban tertiary care centers. J Pure Appl Microbio 2015;9(4):2161-9. 